\title{
Cortical spreading depression in migraine-time to reconsider?
}

\author{
Depressão alastrante cortical na enxaqueca - hora de reconsiderar? \\ Alan J McComas, Adrian R M Upton
}

\begin{abstract}
New evidence concerning the pathophysiology of migraine has come from the results of therapeutic transcranial magnetic stimulation (tTMS). The instantaneous responses to single pulses applied during the aura or headache phase, together with a number of other observations, make it unlikely that cortical spreading depression is involved in migraine. tTMS is considered to act by abolishing abnormal impulse activity in cortical pyramidal neurons and a suggestion is made as to how this activity could arise.
\end{abstract}

Keywords: migraine, spreading depression, transcranial magnetic stimulation.

\section{RESUMO}

Novas evidências referentes à fisiopatologia da enxaqueca são o resultado de estimulação magnética transcraniana terapêutica (tTMS). As respostas imediatas a pulsos simples aplicados durante as fases de aura ou de cefaleia, em associação a diversas outras observações, tornam improvável a ideia de que a depressão alastrante esteja envolvida na enxaqueca. Considera-se que tTMS tenha sua ação abolindo atividade anormal de impulsos em neurônios corticais piramidais, sugerindo que esta atividade tenha um papel desencadeante.

Palavras-chave: enxaqueca, depressão alastrante, estimulação magnética transcraniana.

Three different mechanisms - vascular, trigeminovascular and cortical hyperexcitability - have been proposed for the pathogenesis of migraine and have recently been the subject of extensive reviews ${ }^{1,2,3,4}$. In our own assessment ${ }^{5}$ we presented the results of therapeutic transcranial magnetic stimulation (tTMS) as evidence that, in at least some patients, virtually all migraine symptoms during the headache phase are cortical in origin and that a neuroinflammatory mechanism could not be involved in the initiation and maintenance of the headache; instead, the evidence clearly pointed to cortical hyperexcitability ${ }^{6}$. We now use the results of tTMS once more, this time as part of an argument against one of the central tenets of migraine pathophysiology, namely, that cortical spreading depression (CSD) is responsible for the aura.

\section{CORTICAL SPREADING DEPRESSION (CSD)}

In 1944 Aristides Leão reported the ability to produce temporary suppression of electrical activity in the rabbit cortex by any one of several manoeuvres ${ }^{7}$. The latter included intense electrical stimulation of the brain surface, the application of
$\mathrm{KCl}$ solution, and mechanical deformation. Once induced, the depression of spontaneous EEG activity traveled slowly into neighbouring regions of cortex (Figure 1). The cortical spreading depression (CSD) could be blocked by an incision in the cortex or by the topical application of a local anaesthetic (cocaine $\mathrm{HCl}$ ). Leão subsequently reported that CSD was associated with marked dilatation of the pial arteries and increased blood flow; a smaller vasoconstriction sometimes followed ${ }^{8}$. Leão extended his observations by demonstrating that CSD took place in the more superficial layers of cortex 9 In a final paper, published after his return to Brazil from the United States, Leão described a slow, negative-positive potential that accompanied the onset of EEG suppression ${ }^{10}$.

Leão's observations have been repeatedly confirmed and new observations added. Thus CSD is associated with the efflux of potassium from neurons and glia into the extracellular space, and with a cellular influx of sodium, calcium and water; the concentration of glutamate also rises in the extracellular space ${ }^{11,12}$. The onset of the CSD is associated with depolarization of both astrocytes and neurons, being larger and more rapid in the former ${ }^{13}$. In the neurons there is a transient burst of impulses, which ceases with further depolarization.

McMaster University, Department of Medicine, Hamilton Ontario, Canada.

Correspondence: Alan J McComas; Division of Neurology; Room 4U-1, McMaster University Health Sciences Centre, 1200 Main Street West; Hamilton, Ontario, L8N 3Z5, Canada; E-mail: mccomasa@mcmaster.ca 
It is thought that CSD propagates through the dendritic network and/or through gap junctions between astrocytes.

\section{HISTORICAL LINKAGE OF CSD TO MIGRAINE}

Leão himself speculated that CSD might be linked in some way to migraine, in part because of its slow passage across the cortex; he was, however, thinking in terms of the dilatation of the pial arteries rather than the change in electrical activity. A few years prior to Leão's first publication, the experimental psychologist, Karl Lashley, gave detailed and lucid descriptions of his own visual auras; the scintillations were interpreted as the result of intense excitation in the visual cortex, while the enlarging scotomas were attributed to inhibition ${ }^{14}$. Taking the length of the striate cortex to be $67 \mathrm{~mm}$, and allowing 20 minutes for the visual phenomena to reach the margin of the temporal visual field from their central origin, Lashley calculated that the underlying cortical process traveled rostrally at approximately $3 \mathrm{~mm} /$ minute from the occipital pole. The possible link between CSD and the migraine aura was not pointed out until 1958, in the form of a brief note by Milner ${ }^{15}$. In the following year Hubel and Wiesel published the results of a microelectrode study of the cat visual cortex, reporting the presence of orientation sensitive cells in the primary visual area ${ }^{16}$. The likelihood that excitation of these cells was responsible for the flickering zigzag lines of a visual aura should have been immediately obvious, but instead had to wait 12 years before appearing in print ${ }^{17}$.

The proposition that CSD might be responsible, not only for the visual symptoms but for other types of aura as well, was a logical extension, and one developed by Vincent and Hadjikhani ${ }^{18}$. These authors sent out questionnaires to migraineurs and discovered that many had complex symptoms before the headache; these included difficulties in recognizing objects and faces, in recalling names, and in speech. The authors suggested that the nature and temporal sequence of symptoms could be explained by the course taken by CSD over the surface of the affected hemisphere (Figure 2).

The possibility that CSD might be directly responsible for the headache as well as the aura was suggested by Moskowitz ${ }^{19}$ at the end of a comprehensive review of the innervation of the intracranial arteries. Moskowitz postulated that the rise in extracellular potassium during CSD would depolarize and excite the nociceptive fibres in the ophthalmic division of the trigeminal nerve surrounding the pial arteries; this, by itself, would cause pain, as would reflex changes in the walls of other vessels. The finding of increased levels of CGRP (calcitonin gene related peptide) in jugular venous blood during migraine attacks ${ }^{20}$ was consistent with Moskowitz's scheme, as it suggested that this neuropeptide, perhaps with others, was being liberated from the depolarized trigeminal afferent fibres. In an extension of the hypothesis, Burstein proposed that increased impulse traffic in the same fibres would enhance the excitability of second-order trigeminal neurones in the brain stem, thereby interfering with pain-gating mechanisms ${ }^{21,22}$.

\section{DOES CSD OCCUR IN MIGRAINE?}

As already noted, it is generally accepted that CSD occurs in migraine patients and is responsible not only for a visual aura but for other types of aura as well. After weighing the evidence for and against this concept, including new information gained from single-pulse tTMS, we consider the opposite

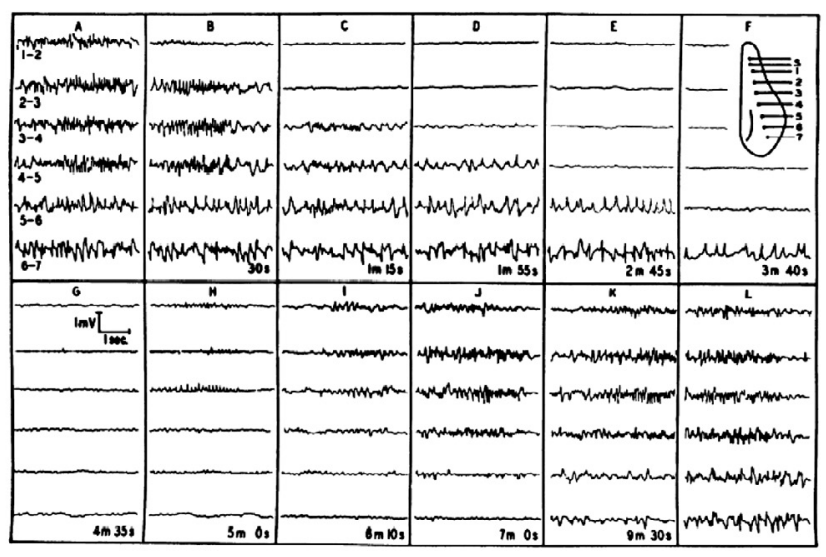

Reproduced from Leão ${ }^{7}$ with permission of the American Physiological Society.

Figure 1. Spreading depression in rabbit brain. Electrical stimuli were delivered through electrodes (S, inset) over frontal cortex, and recordings made through paired electrodes 1-7 placed progressively more posteriorly. Thirty seconds after stimulation there is depression of cortical activity under the nearest pair of recording electrodes (1-2, inset), and within a further 4 minutes the depression has reached the last electrode ( 7 , inset).

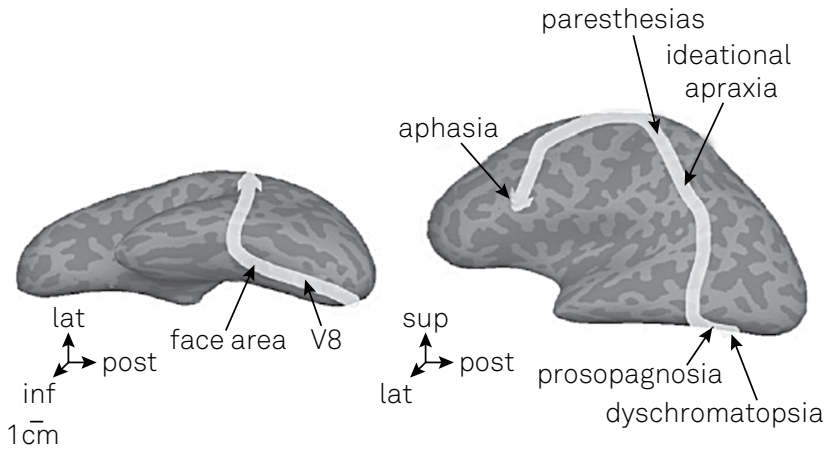

CSD: cortical spreading depression.

Figure 2. Postulated track of CSD in a patient, following initial visual symptoms (dyschromatopsia) and culminating in aphasia ${ }^{18}$. Although CSD is known to have difficulty crossing fissures, in this patient it would have had to travel across 20 or so (dark grey areas in figure). Figure reproduced by permission of Blackwell Publishing. 
to be true - that it is very unlikely that CSD has any place in the pathophysiology of migraine.

\section{Evidence in favour of CSD in migraine Blood flow studies}

As already noted, Leão reported that the spreading depression in exposed rabbit brain was associated with marked dilatation of the pial arteries, with resulting increases in blood flow and in the oxygenation level of the venous blood ('in the veins, the rate of flow is strikingly increased, and these vessels promptly become as scarlet as the $\operatorname{arteries}^{8}$.) The vasodilatation spread outwards in the affected hemisphere, following the depression of neural activity; at a given site it reached its peak in 0.5 - 3 minutes and was over in another 1.5 3 minutes. The vasodilatation was occasionally followed by a prolonged reduction in arterial caliber. Given Leão's description, it was logical to see whether there was altered cortical blood flow during migraine. The initial studies, undertaken in Copenhagen, were based on the detection of regional brain radioactivity at different times following intracarotid injections of radioactive xenon; the testing was undertaken during spontaneous or induced migraine auras ${ }^{23}$. The results were interpreted as evidence of decreased cortical blood flow (oligaemia) during the aura; the reduction was first noted in the posterior part of the brain and it then spread into parietal and temporal areas at a rate of $2-3 \mathrm{~mm} / \mathrm{min}^{24}$; rather similar results were subsequently obtained with PET imaging ${ }^{25}$.

With the advent of functional MRI, it has been possible to examine cortical blood flow with greater temporal and spatial resolution than was previously possible. Perhaps the most impressive results have come from brain oxygen level dependent (BOLD) measurements ${ }^{26}$. In one such study, in which 3 subjects were examined while experiencing a total of 5 visual auras, there was evidence of vasodilatation which began in the visual cortex (area V3A) and traveled slowly over adjacent cortical areas; the vasodilatation was followed by a period of oligaemia ${ }^{27}$. In the example shown in Figure 3, taken from this study, it can be seen that during the vascular changes the BOLD responses of the visual cortex to checkerboard stimulation were diminished. All of these events were consistent with Leão's classical description of CSD, though the authors were careful to conclude that their results were attributable to 'an electrophysiological event such as CSD'.

To summarize this part of the evidence, there can no longer be any doubt that some sort of slowly traveling cortical process is responsible for the visual aura, and presumably for other types of aura. However, although CSD resembles this process in a number of ways, the evidence presently available stops short of proving its presence.

\section{Mutant mouse experiments.}

The ability to introduce, into mice, mutations of the CACN1A1 gene responsible for familial hemiplegic migraine (FHM) has provided a valuable new approach to (studying the pathogenesis of migraine, including the possible role of CSD. The first such mutation to be investigated was R192Q ${ }^{28,29}$ and this was followed by the S218L mutation responsible for a more severe form of $\mathrm{FHM}^{30}$. In both types of knockin mouse model, abnormalities were reported in the CSDs elicited by $100 \mathrm{~ms}$ current pulses; the thresholds were found to be reduced and the rate of spread increased. However, while the results for the homozygous S218 model are strikingly different from those for wild-type mice, the abnormalities described in the heterozygous R192Q model are less convincing. Thus the thresholds for mutant and wild-type mice show 15-fold and 40-fold ranges respectively (Figure 4B), reflecting the difficulty in obtaining consistent values - much of the stimulating current would have been shunted through tissue and cerebrospinal fluid overlying the cortex. Further, although the published figure does indeed show that the passage of CSD between the two recording sites is faster in a mutant than in a wild-type mouse, in both types of mouse the velocity appears to be several times higher between the stimulating electrodes and the nearest recording electrode (Figure 4A).

\section{Anti-migraine drugs and CSD}

Several studies have examined the possibility that anti-migraine drugs might affect CSD, with the implication that a positive finding would provide further, albeit circumstantial, evidence for the role of CSD in the production of aura

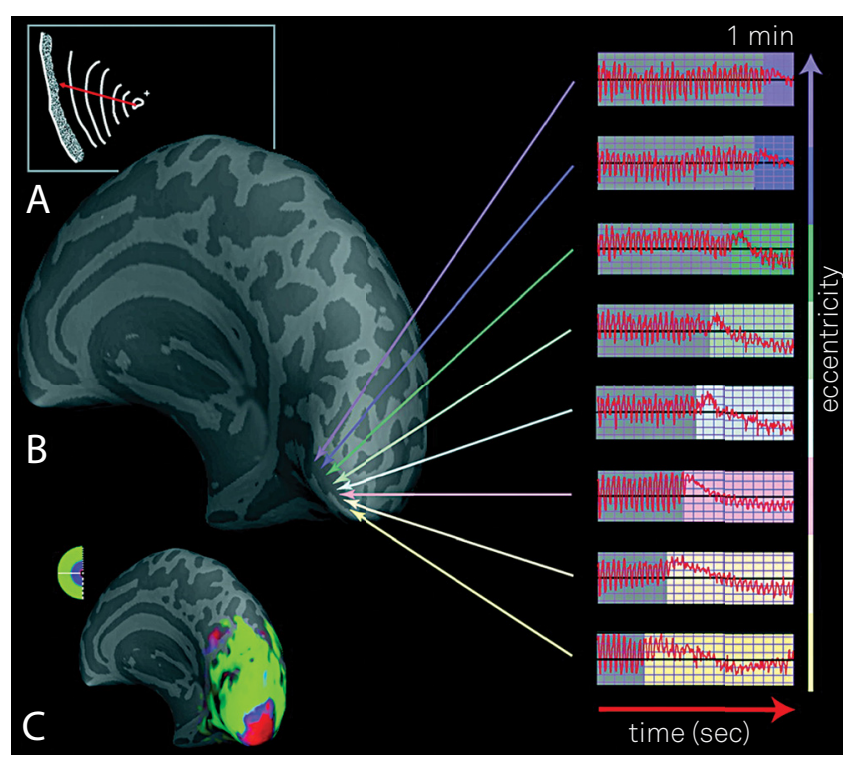

Bold: brain oxygen level dependent.

Figure 3. (A) Progression of scintillations and scotoma in left visual field of a patient with migraine aura. (B) Simultaneous recording of BOLD signals in the medial surface of the right occipital lobe, showing the rostral spread of a diminished response to checkerboard stimulation. (C) Projection of retina on to occipital cortex, as determined by BOLD method (red, blue and green areas represent foveal, parafoveal and peripheral retinal projections respectively). From Hadjikhani et al. ${ }^{27}$, reproduced with permission from the National Academy of Sciences of America. 
A

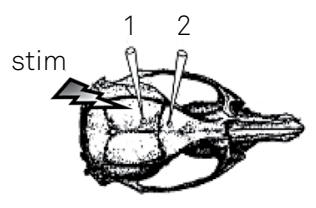

wt
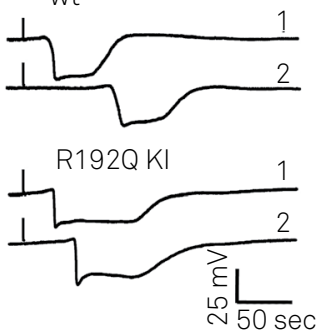

B

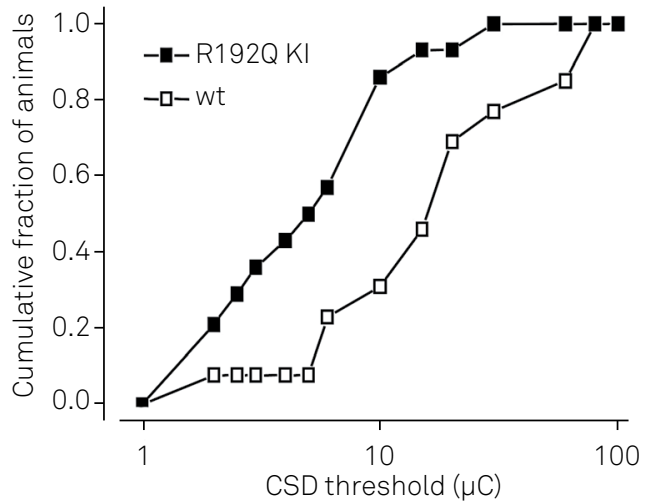

CSD: cortical spreading depression.

Figure 4. (A) Slow waves, associated with spreading depressions, in wild-type (wt) and R192Q K1 mutant mice. Positions of stimulating and recording electrodes shown at top. In the wild type mouse the wave takes approximately $60 \mathrm{~s}$ to travel the $2.1 \mathrm{~mm}$ separating the recording electrodes, for a velocity of $2.1 \mathrm{~mm} / \mathrm{min}$. However, the same wave required only $20 \mathrm{~s}$ or so to travel the $4.8 \mathrm{~mm}$ separating the stimulating electrodes from the nearest recording electrode, corresponding to a velocity of $14.4 \mathrm{~mm} / \mathrm{min}$. The extra distances incurred because of the curvature of the hemispheres have been ignored. (B) Cumulative distributions of thresholds for eliciting CSD in mutant and wild-type mice. From van den Maagdenberg et al. ${ }^{30}$; reproduced with permission of Elsevier.

and headache ${ }^{31}$. The results have been variable; for example, topiramate suppresses CSD effectively inrats ${ }^{32}$ but not in all cats $^{33}$, and in both species the CSD suppression is unaccompanied by changes in bloodflow. In contrast, sumatriptan, a very effective anti-migraine drug, has no effect on $\mathrm{CSD}^{34}$.

\section{Earlier evidence against CSD in migraine: brain recordings and neural function \\ (i). Difficulty in inducing CSD in human subjects}

In his first paper Leão ${ }^{7}$ reported that it was more difficult to evoke CSD in the cat than in the rabbit, and this distinction between brains with convoluted and smooth surfaces has been confirmed ${ }^{35}$. In the human brain, which has many more gyri than the cat, McLachlan and Girvin ${ }^{36}$ were unable to initiate CSD in the exposed cortices of 23 patients about to undergo resections for intractable epilepsy. There are three points that deserve emphasis. First, using the same techniques $(\mathrm{KCl}$ application, electrical and mechanical stimulation), the authors had no difficulty in inducing CSD in rats. Second, the results could not be explained by anaesthesia since the patients were only receiving pain medication with fentanyl and droperidol; though both drugs are known to affect the $\mathrm{EEG}^{37}$, neither appears to interfere with CSD generation ${ }^{38,39}$. Indeed, the fact that droperidol may terminate migraine attacks ${ }^{40}$ and yet not affect CSD constitutes another argument against a role for the latter in the pathogenesis of the headache. Third, four of the patients had suffered from migraine, though without auras. Although there have since been reports of CSD detection in human subjects, using electrocorticography sometimes combined with scalp EEG, it is relevant that the CSD was only associated with major brain lesions, either trauma ${ }^{41}$, subarachnoid haemorrhage or stroke ${ }^{42}$.

\section{EEG recordings during migraine aura}

Although it is technically possible to detect CSD in human subjects with scalp electrodes (see above), any depression of EEG activity during either the aura or the headache phase of migraine is mild or absent; there may be some increase in slow wave activity but, in a proportion of patients, the EEG may be quite normal ${ }^{43}$.

\section{Preservation of neural function during the aura}

It is well known that sensory function may be lost during an aura, the best example being the scotoma that replaces the scintillations as the latter progress across the visual field. However, the association is not invariable, for in a minority of subjects the fortification spectra may be superimposed on a normal visual image. Similarly, subjects who describe numbness and tingling can still detect touch. Such preservation of function is incompatible with a process, such as CSD, that, at least in animal models, abolishes all neural activity.

\section{New evidence against CSD in migraine: therapeutic transcranial magnetic stimulation}

Transcranial magnetic stimulation (TMS) has been employed as a means of exploring CNS function for almost 30 years, its great advantage over electrical stimulation being that it is painless and penetrates the skull more readily; nevertheless the magnetic pulse is converted to an electrical one on intersecting suitably disposed biological conductors (axons and dendrites). Depending on the choice of target and stimulus parameters, TMS can be employed to either excite or block function in a neural circuit ${ }^{44}$. The possibility of TMS being a useful treatment for migraine was raised in 2004 when it was found that a course of repetitive 
TMS, when applied to the left dorsolateral prefrontal cortex on alternate days, reduced both the frequency and the intensity of migraine attacks; moreover, the benefit persisted for at least one month ${ }^{45}$. Similar, but unexpected, findings were subsequently reported in two migraineurs treated in a similar way for depression ${ }^{46}$. Our own interest in tTMS for migraine arose from observations made on one of the authors, a migraine sufferer himself, and on patient volunteers ${ }^{47}$. Unlike the aforementioned studies, TMS was applied at the onset of the headache and given as a single pulse, sometimes repeated once, to the back of the head; the headache was found to diminish and sometimes to disappear altogether. The working hypothesis - a mistaken one (see below) - was that stimulation of the cortex in advance of a CSD was halting the progress of the latter, rather as the creation of a firebreak may stop a forest fire. Any CSD present during the attack was presumed to have commenced in the occipital cortex, since visual symptoms constitute the most common aura. Since that time there have been several controlled trials of single or double pulse TMS administered to the occipital cortex during the migraine attack, and in all cases there have been positive outcomes ${ }^{5,48,49,50,51}$. In the latter two trials, the patients were able to deliver the magnetic pulses themselves, using a portable hand-held device designed specifically for that purpose.

While the above studies were conceived on the basis of a pivotal role for CSD in migraine, additional studies with tTMS made it unlikely that CSD is responsible for either the aura or the headache. The crucial observation was that, in some subjects, the effects of tTMS were immediately apparent. No one showed this effect more convincingly than K.B., a 71-year old woman with a long history of familial migraine, initially basilar in its symptomatology but later progressing to daily episodes associated with multiple body pains, tingling, hallucinations, quadriplegia, coma and respiratory arrest ${ }^{5,52,53}$. It was found that, when directed to the appropriate site on the hemisphere opposite to the symptoms, tTMS could abolish each symptom instantaneously (Figure 5). The significance of the rapidity of action of tTMS is considered below, while Table summarizes the evidence for, and against, a role for CSD in the genesis of aura and headache in migraine.

\section{Mode of action of electrical (and magnetic) stimulation of cortex}

The results of tTMS make it clear that CSD could not be involved in either the aura or the headache of migraine. The first reason is that, as Leão described in his first paper, electrical stimulation (and hence TMS) is unable to stop CSD, whether applied before or after the traveling disturbance reaches the stimulus location on the cortex ${ }^{7}$. The second reason is that CSD involves such a profound disturbance of water, electrolytes and neurotransmitters, that it is inconceivable that these could be corrected instantly by any means, including TMS. Clearly, then, TMS is doing something else, but what?

The first attempt to understand the local effects of stimulating the cortex appears to have been made by Adrian ${ }^{54}$ in anaesthetized rabbits; he recorded a local negativity generated by superficial elements in the cortex. With stronger, repeated stimulation the evoked surface potentials became positive due to depolarization of deeper cortical structures; at the same time the responses spread further across the cortex. Much later Krnjevic et al. ${ }^{5}$ showed that single cortical shocks, especially when applied to the deeper layers,

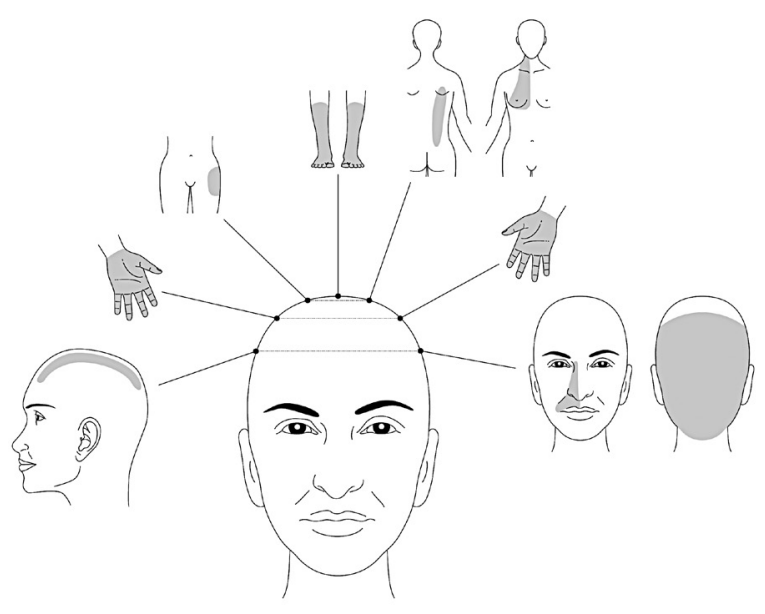

TMS: transcranial magnetic stimulation.

Figure 5. Optimal TMS tilted coil placements for abolishing different regions of pain (shaded) in patient KB, at the start of her treatment in July 2004. From McComas ${ }^{53}$. The positions roughly correspond to the homoncular map in the postcentral gyrus, as determined by Penfield \& Boldrey ${ }^{62}$.

Table. Summary of evidence for and against a causal role for CSD in migraine

\begin{tabular}{|c|c|}
\hline Evidence Regarding CSD In Migraine & \\
\hline FOR & AGAINST \\
\hline Similar velocities of CSD and cortical aura mechanism $m^{7,14}$ & High CSD threshold in humans ${ }^{36}$ \\
\hline Cortical hypoperfusion during aura $23,24,25,26,27$ & Persisting EEG during migraine ${ }^{43}$ but not during $\mathrm{CSD}^{7}$ \\
\hline CSD abnormalities in S218 mouse model of migraine ${ }^{30}$ & Persisting sensory function during aura in some subjects \\
\hline Effect of anti-migraine compounds on CSD 32,33 & Instant abolition of aura, headache by single-pulse TMS ${ }^{5,52}$ \\
\hline & CSD not arrested by electric (and hence TMS) pulse ${ }^{7}$ \\
\hline & Non-effect of anti-migraine compounds on CSD ${ }^{34}$ \\
\hline
\end{tabular}

CSD: cortical spreading depression; tTMS: therapeutic transcranial magnetic stimulation. 
produced powerful inhibition of spontaneous and evoked neural activity in the cortex. In a second paper the same authors identified basket cells as the inhibitory neurones; these cells were at the appropriate depth and their axon terminals formed nests around the bodies of the pyramidal cells ${ }^{56}$.

While the excitation of the basket cells would account for the ability of a single TMS pulse to abruptly stop ongoing activity in pyramidal cells producing migraine symptoms, the cause of the latter activity remains elusive. One explanation is that the activity is generated by high frequency oscillations in the distal axons of pyramidal cells, and impulses then travel antidromically and excite the cell bodies (Figure 6). Normally this back-propagation would be prevented by intervening axoaxonic inhibitory synapses ${ }^{57}$. Another, not exclusive, possibility is that the activity in the pyramidal cells is triggered by fast rhythmic bursting neurones in the cortex ${ }^{58}$. In either instance the spread of the excitatory activity, and hence the spread of migraine symptoms, would be mediated by gap junctions reported to exist between the axons of pyramidal cells ${ }^{59}$.

\section{The emerging picture}

On the basis of the findings and considerations reported above, it is now possible to suggest what may actually be happening in the brain during an attack of migraine:

(i). Almost all the varied symptoms of migraine, including the headache, arise from abnormal impulse activity in the pyramidal cells within the outer layers (II and III) of the cerebral cortex; it is such cells in the primary somatosensory receiving area (S1) that are responsible for the headache. The cause of the neural hyperactivity is not known; back-propagation of impulses from the distal axon is only one of several possibilities. At a molecular level the defect could involve altered calcium fluxes at synapses, in keeping with results in mutant mice expressing the CACN1A gene, but other mechanisms are possible. Diminished serotonergic control of the cortex from the brain stem is a different type of mechanism that may also operate. Whatever the cause of the hyperactivity in pyramidal cells, the process slowly spreads, probably through gap junctions between axons.

(ii). The transiently hyperactive cells in V1 (the primary visual area), responsible for the fortification spectra during a visual aura, are the orientation-sensitive ones. However, V1 also contains colour-sensitive cells and excitation of these accounts for the coloured 'blobs' experienced by some patients in their auras.

(iii). The spreading mechanism is not confined to the visual cortex, but may occur in the somatosensory cortex as well. An example is given by Liveing in his classic monograph, in which a patient 'felt a numbness in her right leg, ascending to the trunk, right arm and face' ${ }^{60}$.

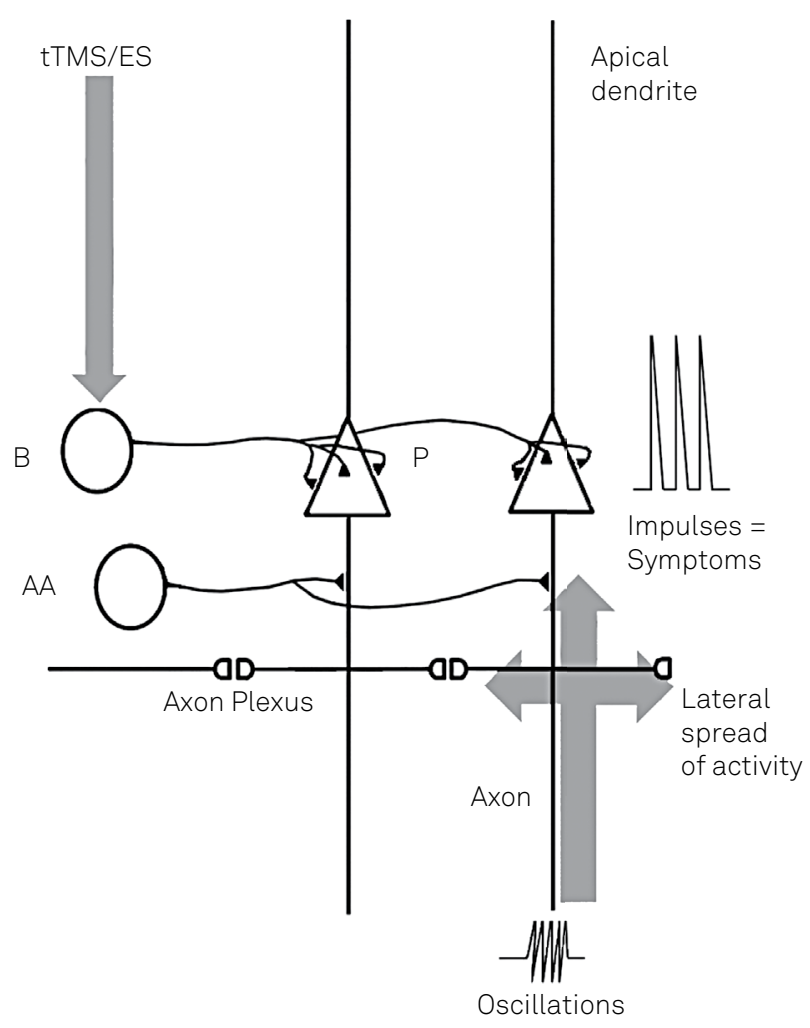

tTMS: therapeutic transcranial magnetic stimulation.

Figure 6. Hypothetical scheme to explain the spreading neural activity responsible for migraine auras and headache. Fast oscillatory activity is present in the distal axons of principal pyramidal neurons $(P)$ in cortical layers 2-4. This activity produces 'spikelets' which travel back towards the cell bodies of the P neurons and also across gap junctions formed with neighbouring axons (the axon plexus), causing a slow spread of activity in the cortex. The spikelets do not usually invade the cell bodies because of intervening inhibitory synapses from axoaxonic cells (AA); should the latter not operate, however, the spikelets will set off fully formed impulses in the P cells, causing migraine symptoms. tTMS and electrical stimulation (ES) are effective because they stimulate the basket cells (B), which then powerfully inhibit the P cells. The scheme is based on work by Traub et al. ${ }^{59}$ and Dugladze et al. ${ }^{57}$.

(iv). The presence of multiple symptoms preceding or during the headache is due to independent islands of cortical hyperactivity, rather than to spread of hyperactivity over long distances. This conclusion comes from the observation that different symptoms can occur within seconds of each other, as in patient $\mathrm{KB}$ described earlier ${ }^{5,53}$.

(v). During an attack of migraine TMS can be instantaneously effective by exciting the cortical basket cells and thereby inhibiting the firing of the pyramidal cells.

(vi). Finally and importantly, cortical spreading depression is not involved in either the aura or the headache of migraine. It would therefore be appropriate to refer to the process responsible for these phenomena simply as 'migrainous neural activity' (MNA). 


\section{UNANSWERED QUESTIONS}

As already noted, we do not know what sets off the excessive impulse activity in the cortical pyramidal cells, though possible mechanisms have been identified. Similarly, it is not clear why tTMS should work in some patients and not in others, nor is it obvious why the reduction in the intensity of the headache may sometimes take several minutes to appear. Again, why should it be possible to improve the headache by applying tTMS to the back of the head, when the headache is due to neural activity in the primary somatosensory area? We also need to learn why, in a severely affected patient, the optimal site for tTMS may move and the intervention eventually lose its efficacy, as was the case with patient $\mathrm{KB}^{61}$ (see above and Figure 7). Though these questions remain to be answered, it is our submission that the elimination of cortical spreading depression as a migraine mechanism is an important step in resolving the pathophysiology of this puzzling disorder.

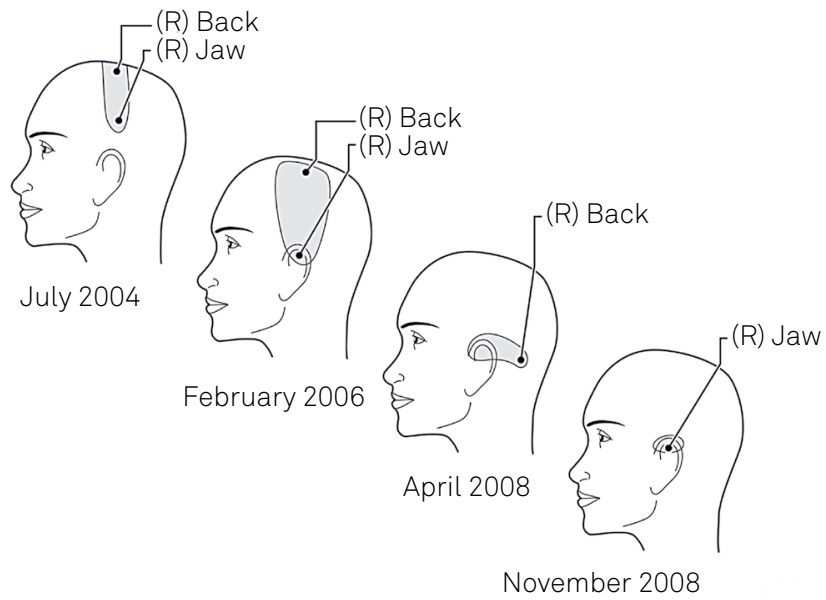

tTMS: therapeutic transcranial magnetic stimulation.

Figure 7. Changes in the optimal coil positions for K. B. over a 4-yr period. Eventually only the pain in her right jaw responded to tTMS, and this effect was lost 6 months later (July 2009).

From McComas ${ }^{61}$, courtesy of the Polish Academy of Sciences.

\section{References}

1. Goadsby PJ, Charbit AR, Andreou AP, Akerman S, Holland PR. Neurobiology of migraine. Neuroscience. 2009;161(2):327-41. http://dx.doi.org/10.1016/j.neuroscience.2009.03.019

2. Tietjen GE. Migraine as a systemic vasculopathy. Cephalalgia. 2009;29(9):989-996. http://dx.doi.org/10.1111/j.1468-2982.2009.01937.x

3. Cutrer FM. Pathophysiology of migraine. Semin Neurol. 2010;30(2):120-30. http://dx.doi.org/10.1055/s-0030-1249222

4. Pietrobon D, Moskowitz MA. Pathophysiology of migraine. Ann Rev Physiol, 2013;75:365-91. http://dx.doi.org/10.1146/annurev-physiol-030212-183717

5. McComas A, Upton A. Therapeutic transcranial magnetic stimulation in migraine and its implications for a neuroinflammatory hypothesis. Inflammopharmacology. 2009;17(2):68-75. http://dx.doi.org/10.1007/s10787-009-8058-7

6. Aurora SK, Wilkinson F. The brain is hyperexcitable in migraine. Cephalalgia. 2007;27(12):1442-53. http://dx.doi.org/10.1111/j.1468-2982.2007.01502.x

7. Leão AAP. Spreading depression of activity in the cerebral cortex.J Neurophysiol. 1944;7(6):359-90.

8. Leão AAP. Pial circulation and spreading depression of activity in the cerebral cortex.J Neurophysiol. 1944;7(6):391-6.

9. Leão AAP, Morison RS. Propagation of spreading cortical depression. J Neurophysio.l 1945;8(1):33-45.

10. Leão AAP. Further observations on the spreading depression of activity in the cerebral cortex.J Neurophysiol. 1947;10(6):409-14.

11. Smith JM, Bradley DP, James MF, Huang CL-H. Physiological studies of cortical spreading depression. Biol Rev Camb Philos Soc. 2006;81(4):457-81. http://dx.doi.org/10.1017/\$1464793106007081

12. Charles A, Brennan KC. Cortical spreading depression-new insights and persistent questions. Cephalalgia. 2009;29(10):1115-24. http://dx.doi.org/10.1111/j.1468-2982.2009.01983.x

13. Sugaya $E$, Takato M, Noda Y. Neuronal and glial activity during spreading depression in cerebral cortex of cat. J Neurophysiol. 1975;38(4):822-41.

14. Lashley KS. Patterns of cerebral integration indicated by the scotomas of migraine. Arch Neurol Psychiatry. 1941;46(2):331-9. http://dx.doi.org/10.1001/archneurpsyc.1941.02280200137007
15. Milner PM. Note on a possible correspondence between the scotomas of migraine and spreading depression of Leão. Electroencephalogr Clin Neurophysiol. 1958;10(4):705. http://dx.doi.org/10.1016/0013-4694(58)90073-7

16. Hubel DH, Wiesel TN. Receptive fields of single neurons in the cat striate cortex.J Physiol. 1959;148(3)-574-91. http://dx.doi.org/10.1113/jphysiol.1959.sp006308

17. Richards W. The fortification illusions of migraine. Sci Am. 1971;224:88-96

18. Vincent MB, Hadjikhani N. Migraine aura and related phenomena: beyond scotomata and scintillations. Cephalalgia. 2007:27(12):1368-77. http://dx.doi.org/10.1111/j.1468-2982.2007.01388.x

19. Moskowitz MA. The neurobiology of vascular head pain. Ann Neurol. 1984;16(2):157-68. http://dx.doi.org/10.1002/ana.410160202

20. Goadsby PJ, Edvinsson L, Ekman R. Vasoactive peptide release in the extracerebral circulation of humans during migraine headache. Ann Neurol. 1990;28(2):183-7. http://dx.doi.org/10.1002/ana.410280213

21. Burstein R. Deconstructing migraine headache into peripheral and central sensitization. Pain. 2001;89(2-3):107-10. http://dx.doi.org/10.1016/S0304-3959(00)00478-4

22. Noseda R, Burstein R. Migraine pathophysiology: anatomy of the trigeminovascular pathway and associated neurological symptoms, cortical spreading depression, sensitization, and modulation of pain. Pain. 2013;154:S44-53. http://dx.doi.org/10.1016/j.pain.2013.07.021

23. Olesen J, Larsen B, Lauritzen M. Focal hyperemia followed by spreading oligemia and impaired activation of rCBF in classic migraine. Ann Neurol. 1981;9(4):344-52. http://dx.doi.org/10.1002/ana.410090406

24. Lauritzen M. Pathophysiology of the migraine aura. The spreading depression theory. Brain. 1994;117(1):199-210. http://dx.doi.org/10.1093/brain/117.1.199

25. Woods RP, lacoboni M, Mazziotta JC. Brief report: bilateral spreading cerebral hypoperfusion during spontaneous migraine headache. N Engl J Med. 1994;331(25):1689-92. http://dx.doi.org/10.1056/NEJM199412223312505

26. Cao Y, Welch KM, Aurora S, Vikingstad EM. Functional MRI-BOLD of visually triggered headache in patients with migraine. Arch Neurol. 1999;56(5):548-54. http://dx.doi.org/10.1001/archneur.56.5.548 
27. Hadjikhani N, Sanchez del Rio M, Wu O, Schwartz D, Bakker D, Fischl $B$ et al. Mechanisms of migraine aura revealed by functional MRI in human visual cortex. Proc Natl Acad Sci USA. 2001;98(8):4687-92. http://dx.doi.org/10.1073/pnas.071582498

28. Maagdenberg AM, Pietrobon D, Pizzorusso T, Kaja S, Broos LA, Cesetti T et al. A Cacna 1a knockin migraine mouse model with increased susceptibility to cortical spreading depression. Neuron. 2004;41(5):701-10. http://dx.doi.org/10.1016/S0896-6273(04)00085-6

29. Cao YQ, Piedras-Rentería ES, Smith GB, Chen G, Harata NC, Tsien RW. Presynaptic $\mathrm{Ca}^{2+}$ channels compete for channel type-preferring slots in altered neurotransmission arising from $\mathrm{Ca}^{2+}$ channelopathy. Neuron. 2004;43(3):387-400. http://dx.doi.org/10.1016/j.neuron.2004.07.014

30. Maagenberg AM, Pizzorusso T, Kaja S, Repolilli N, Shapovalova M, Hoebeek FE et al. High cortical spreading depression susceptibility and migraine-associated symptoms in $\mathrm{Ca}_{\mathrm{v}} 2.1 \mathrm{~S} 218 \mathrm{~L}$ mice. Ann Neurol. 210;67(1):85-98. http://dx.doi.org/10.1002/ana.21815

31. Costa C, Tozzi A, Rainero I, Cupini LM, Calabresi P, Ayata C et al. Cortical spreading depression as a target for anti-migraine agents. J Headache Pain. 2013;14(1):62. http://dx.doi.org/10.1186/1129-2377-14-62

32. Unekawa M, Tomita Y, Toriumi H, Suzuki N. Suppressive effect of chronic peroral topiramate on potassium-induced cortical spreading depression in rats. Cephalalgia. 2012;32(7):518-27. http://dx.doi.org/10.1177/0333102412444015

33. Akerman S, Goadsby PJ. Topiramate inhibits cortical spreading depression in rat and cat: impact in migraine aura. Neuroreport. 2005;16(2):1383-7. http://dx.doi.org/10.1097/01.wnr.0000175250.33159.a9

34. Read SJ, Hirst WD, Upton N, Parsons AA. Cortical spreading depression produces increased cGMP levels in cortex and brain stem that is inhibited by tonabersat (SB-220453) but not sumatriptan. Brain Res. 2001;89(1-2):69-77. http://dx.doi.org/10.1016/S0006-8993(00)03191-7

35. Marshall WH, Essig CF. Relation of air exposure of cortex to spreading depression of Leão.J Neurophysiol. 1951;14(4):265-73.

36. McLachlan RS, Girvin JP. Spreading depression of Leão in rodent and human cortex. Brain Res. 1994;666(1):133-6. http://dx.doi.org/10.1016/0006-8993(94)90295-X

37. Kushikata T, Araki I, Sato T, Hashimoto Y, Ishihara H, Matsuki A. [EEG pattern during total intravenous anesthesia with droperidol, fentanyl and ketamine]. Matsui. 1993;42(8):1194-9. Japanese.

38. Hunfeld M, Pope KJ, Fitzgibbon SP, Willoughby JO, Broberg M. Effects of anesthetic agents on seizure-induction with intra-cortical injection of convulsants. Epilepsy Res. 2013;105(1-2):52-61. http://dx.doi.org/10.1016/j.eplepsyres.2012.12.009

39. Hertle DN, Dreier JP, Woitzik J, Hartings JA, Bullock R, Okonkwo DO et al. Effect of analgesics and sedatives on the occurrence of spreading depolarizations accompanying acute brain injury. Brain. 2012;135(8):2390-8. http://dx.doi.org/10.1093/brain/aws152

40. Nerenberg RH, Friedman BW. Migraine: an evidence-based update. Emerg Med. 2014;46(7):294-316.

41. Fabricius M, Fuhr S, Bhatia R, Boutelle M, Hashemi P, Strong AJ et al. Cortical spreading depression and peri-infarct depolarization in acutely injured human cerebral cortex. Brain. 2006;129(3):778-90. http://dx.doi.org/10.1093/brain/awh716

42. Drenckhahn C, Winkler MKL, Major S, Scheel M, Kang EJ, Pinczolits A et al. Correlates of spreading depolarization in human scalp electroencephalography. Brain. 2012;135(3):853-68. http://dx.doi.org/10.1093/brain/aws010

43. Sand T. EEG in migraine: a review of the literature. Funct Neurol. 1991;6(1):7-22.
44. Hallett M. Transcranial magnetic stimulation and the human brain. Nature. 2000;406(6792):147-50. http://dx.doi.org/10.1038/35018000

45. Brighina F, Piazza A, Vitello G, Aloisio A, Palermo A, Daniele $O$ et al. rTMS of the prefrontal cortex in the treatment of chronic migraine:a pilot study.J Neurol Sci. 2004;227(1):67-71. http://dx.doi.org/10.1016/j.jns.2004.08.008

46. O'Reardon JP, Fontecha JF, Cristancho MA, Newman S. Unexpected reduction in migraine and psychogenic headaches following rTMS treatment for major depression: a report of two cases. CNS Spectr. 2007;12(12):921-5. http://dx.doi.org/10.1017/\$1092852900015716

47. Fisher MJ. Goodbye headaches: a gun that shoots magnetic pulses puts and end to an age-old scourge. Discover. 2004;25(8):28-9.

48. Clarke BM, Upton ARKamath MV, Al-Harbi T, Castellanos CM. Transcranial magnetic stimulation for migraine:clinical effects.J Headache Pain. 2006;7(5):341-6. http://dx.doi.org/10.1007/s10194-006-0329-8

49. Mohammed YM, Hughes G, Kothari R, Nkrumah M, Fischell S, Robert F et al. Self-administered transcranial magnetic stimulation (TMS) during the aura phase improves and aborts headaches. Headache. 2006;46:839.

50. Lipton RB, Dodick DW, Silberstein SD, Saper JR, Aurora SK, Pearlman SH et al. Single-pulse transcranial magnetic stimulation for acute treatment of migraine with aura: a randomised, double-blind, parallel-group, sham-controlled trial. Lancet Neurol. 2010;9(4):373-80. http://dx.doi.org/10.1016/S1474-4422(10)70054-5

51. Lipton RB, Pearlman SH. Transcranial magnetic stimulation in the treatment of migraine. Neurotherapeutics. 2010;7(2):204-12. http://dx.doi.org/10.1016/j.nurt.2010.03.002

52. Upton A, McComas A. Abolition of migraine by transcranial magnetic simulation. Abstracts of 40th Meeting of the Canadian Congress of Neurological Sciences; 2005 June 14-18; Otawwa. CalgarY: Canadian Congress of Neurological Sciences; 2005. (Can J Neurol Sci. 2005;32(2 suppl 1):S71.

53. McComas AJ. The artful chameleon: an exploration of migraine and medicine. West Flamborough: Alkat Neuroscience; 2006.

54. Adrian ED. The spread of activity in the cerebral cortex.J Physiol. 1937;88(2):127-61. http://dx.doi.org/10.1113/jphysiol.1936.sp003427

55. Krnjević K, Randić M, Straughan DW. An inhibitory process in the cerebral cortex. J Physiol. 1966;184(1):16-48. http://dx.doi.org/10.1113/jphysiol.1966.sp007902

56. Krnjević K, Randić M, Straughan DW. Nature of a cortical inhibitory process. J Physiol. 1966;184(1):49-77. http://dx.doi.org/10.1113/jphysiol.1966.sp007903

57. Dugladze T, Schmitz D, Whittington MA, Vida I, Gloveli T. Segregation of axonal and somatic activity during fast network oscillations. Science. 2012;336(6087):1458-61. http://dx.doi.org/10.1126/science.1222017

58. Cunningham MO, Whittington MA, Bibbig A, Roopun A, LeBeau FE, Vogt A et al. A role for fast rhythmic bursting neurons in cortical gamma oscillations in vitro. Proc Natl Acad Sci USA. 2004;101(18):7152-7.

59. Traub R, Bibbig A, LeBeau FE, Cunningham MO, Whittington MA. Persistent gamma oscillations in superficial layers of rat auditory neocortex: experiment and model. J Physiol. 2005;562(1):3-8. http://dx.doi.org/10.1113/jphysiol.2004.074641

60. Liveing E. On megrim, sick-headache and some allied disorders: a contribution to the pathology of nerve-storms. London: Churchill; 1873.

61. McComas AJ. TMS in a severe case of complex migraine. Lecture Notes of the ICB Seminar. 2009;83:164-9.

62. Penfield W, Boldrey E. Somatic motor and sensory representation in the cerebral cortex of man as studied by electrical stimulation. Brain. 1937;60(4):389-443. http://dx.doi.org/10.1093/brain/60.4.389 